\title{
Epigenetics in systemic lupus erythematosus (Review)
}

\author{
GONG XIAO and XIAOXIA ZUO \\ Department of Rheumatology, Xiangya Hospital, Central South University, Changsha, Hunan 410008, P.R. China
}

Received October 19, 2015; Accepted December 4, 2015

DOI: $10.3892 /$ br.2015.556

\begin{abstract}
Systemic lupus erythematosus (SLE) is a multisystem autoimmune disease, with mechanisms that remain to be elucidated. Previous studies have proposed that genes and environments are required for lupus to develop and flare. It has been found that epigenetics have a significant influence on SLE. The present review will concentrate on epigenetics in SLE. There are a number of studies reporting that autoreactive T cells and B cells in patients with SLE have evidence of altered patterns of DNA methylation, modifications of histones and microRNA (miRNA). Long noncoding RNAs (lncRNAs) are another type of noncoding RNAs, which have an important role in epigenetics. IncRNAs may possibly become a new hotspot in SLE.
\end{abstract}

\section{Contents}

1. Introduction

2. Epigenetics

3. DNA methylation abnormalities

4. Histone modifications and SLE

5. Noncoding RNAs and SLE

6. Conclusion

\section{Introduction}

Autoimmune diseases arise from the dysfunction of the immune system, which results in the inflammation and the damage of tissues and organs. Innate and adaptive immunity contribute to the mechanism of diseases (1). Systemic lupus erythematosus (SLE) is a multisystem autoimmune disease that is characterized by immune complex accumulation in blood vessels and connective tissue (2).

Correspondence to: Dr Xiaoxia Zuo, Department of Rheumatology, Xiangya Hospital, Central South University, Ward No. 48, Building A 87 Xiangya Road, Changsha, Hunan 410008, P.R. China

E-mail: nktb@163.com

Key words: epigenetics, lupus
The etiology and pathogenesis of SLE remain to be elucidated. It is believed that the etiological factors include the genetic susceptibility, environmental factors and epigenetics. Recent genome-wide association studies (GWAS) and fine mapping of candidate genes or regions have considerably broadened the understanding of this complex autoimmune disease. At present, $>100$ gene variations/alleles from different ethnicities are known, which are genetic risk factors for lupus (3). Another study of GWAS of several thousand allelic variants (single nucleotide polymorphisms) in case-control studies have identified $>30$ genes involved in SLE (4). Environmental factors, such as ultraviolent light, smoking and alcohol, have an important role in the pathophysiology of SLE (5). The combination of genetic abnormalities, environmental factors and their interactions contribute to the induction of SLE $(6,7)$. Epigenetic dysregulation has recently been reported to have a critical role in the pathogenesis of SLE (8).

\section{Epigenetics}

Epigenetic information is carried chiefly by DNA itself, histones and noncoding RNAs (ncRNAs). It has been found that epigenetic dysregulation occurs generally in lupus.

\section{DNA methylation abnormalities}

DNA methylation is one of the epigenetic mechanisms. It suppresses gene expression by methylating the deoxycytosine base at the 5 ' position to form deoxymethylcytosine (9). DNA hypomethylation, an epigenetic modification, can influence gene expression and has been implicated in the pathogenesis of SLE. The gene can lead to decreased or silenced gene expression by the methylation of $\mathrm{C}-\mathrm{G}$ dinucleotides $(\mathrm{CpG})(10,11)$. Lupus patients exhibit global T-cell hypomethylation (12). The genes include a number of autoimmune-related genes, such as ITGAL [cluster of differentiation 11a (CD11a)] and TNFSF7 (CD70) $(13,14)$. CD11a, perforin and the KIR genes were overexpressed in patients with active, but not inactive, lupus, and the same sequences demethylated in proportion to disease activity and gene overexpression in these patients $(15,16)$. CD4 ${ }^{+} \mathrm{T}$ cells from idiopathic SLE patients are significantly hypomethylated compared to healthy control CD4 ${ }^{+} \mathrm{T}$ cells (17). The $\mathrm{X}$ chromosome of SLE women is demethylated, which may be the reason of the predominance of SLE in women $(18,19)$. A genome-wide DNA methylation study in $\mathrm{CD}^{+} \mathrm{T}$ cells in lupus patients compared to normal healthy controls identified that there are 105 hypermethylated 
and 236 hypomethylated CG sites in the 27,578 CG sites located within the promoter regions of 14,495 genes (20). There is another study regarding genome-wide DNA methylation study in two independent sets of lupus patients and matched healthy controls, which characterized the DNA methylome in naïve $\mathrm{CD} 4^{+} \mathrm{T}$ cells in lupus. The study quantified for $>485,000$ methylation sites across the genome, and identified and replicated 86 differentially methylated CG sites between patients and controls in 47 genes, with the majority being hypomethylated through gene expression analysis from the same cells to investigate the association between the DNA methylation changes observed and mRNA expression levels. Significant hypomethylation has been observed to interfere on regulated genes in naïve $\mathrm{T}$ cells from lupus patients, including IFIT1, IFIT3, MX1, STAT1, IFI44L, USP18, TRIM22 and BST2, which suggested epigenetic transcriptional accessibility in these genetic loci (21). Hypomethylation of $\mathrm{CpG}$ sites within genes from different pathways has also been reported to be associated with anti-double stranded DNA (dsDNA), anti-SSA, anti-Sm and anti-ribonucleoprotein production in SLE (22). The plasma DNA of active SLE patients showed decreased methylation densities. The extent of hypomethylation correlated with SLEDAI and the anti-dsDNA antibody level. SLE patients had higher concentrations of immunoglobulin $\mathrm{G}$ (IgG)-bound DNA in plasma (23). The hypomethymethylation of plasma DNA may be accessible for IgG to bind DNA. DNA methylation mechanisms are involved in SLE.

\section{Histone modifications and SLE}

Histones are a group of proteins wrapping the DNA to form the chromosomal structure nucleosome. The post-translational modifications of histone proteins have been identified as one of the major epigenetic mechanisms in government of chromatin remodeling and gene expression through phosphorylation, acetylation, and methylation and so on (24). In CD4 ${ }^{+} \mathrm{T}$ cells of SLE patents, it has been identified that global histone $\mathrm{H} 3$ and $\mathrm{H} 4$ are hypoacetylated and global histone $\mathrm{H} 3 \mathrm{~K} 9$ is hypomethylated. The results indicated that the modifications of histones are involved in the pathogenesis of SLE $(25,26)$. Acetylated histones contribute to the immunostimulatory potential of neutrophil extracellular traps (NETs) in systemic lupus erythematosus (27). It was found that the histone acetyltransferases (HATs) and histone deacetylases (HDACs) were abnormal in patients with active SLE (25). In another study, isoaspartic acid (isoAsp) was reported as a modification that triggers B-and T-cell autoimmunity to otherwise inert self-peptides and T-cell autoimmunity to otherwise inert self-peptides (28). H2B is the only histone that has isoAsp modification, which has contributed to recognition of $\mathrm{H} 2 \mathrm{~B}$ by $\mathrm{B}$ cells and development of the antibodies to this particular histone (29). The specific post-translational histone modifications of NETs could be immunogens and potential targets of lupus autoantibodies (30). Protein phosphatase $2 \mathrm{~A}$ is involved in the regulation of the interleukin (IL)-17 locus by enhancing histone $\mathrm{H} 3$ acetylation through a mechanism that involves activation of interferon regulatory factor 4 . This process contributes to the pathogenesis of SLE (31). The inhibition of histone deacetylase can upregulate B-cell microRNAs (miRNAs) that silence AICDA/Aicda (AID) and PRDM1/Prdm1 (Blimp-1), contributing to B-cell differentiation processes that underpin antibody and autoantibody responses in lupus MRL/Faslpr/lpr mice (32). HDAC inhibitors are also able to ameliorate renal lesions in lupus nephritis (LN) (33). A clinical study also showed that mycophenolic acid could upregulate the level of histone $\mathrm{H} 3 / \mathrm{H} 4$ global acetylation by regulating HATs and HDACs in lupus CD4 ${ }^{+} \mathrm{T}$ cells and affected the histone $\mathrm{H} 4$ acetylation and histone $\mathrm{H} 3 \mathrm{~K} 4$ tri-methylation levels in the CD40L promoter region that inhibited the expression of CD40L, which indicates the potential epigenetic mechanism of therapeutic effects in SLE (34). The structural alterations and immunogenicity of histones following glycation and oxidation reactions are involved in the pathological process of SLE (35). Peroxynitrite-modified H1 histone induced high titre antibodies and binding of SLE autoantibodies involved in SLE etiopathogenesis (36). 4-Hydroxy-2-nonenal modified histone $\mathrm{H} 2 \mathrm{~A}$ may also become an antigenic stimulus for SLE autoantibodies (37). DNA methylation and histone modifications can regulate gene expression together. The transcription factor cAMP-responsive element modulator- $\alpha$ represses IL-2 expression through histone deacetylation and CpG-DNA methylation in SLE T cells (21).

\section{Noncoding RNAs and SLE}

ncRNA were previously regarded as 'junk and noise'; however, recently it was suggested that ncRNA has a critical role in physiological processes that maintain cellular and tissue homeostasis (38-40). ncRNAs are grouped into two major classes according to the transcript size: Small ncRNAs [<200 nucleotides (nt)], such as miRNAs, and long ncRNAs ( $\geq 200 \mathrm{nt})$. miRNAs have a role in regulating protein coding genes, such as the binding of transcription factors or enhancers to the cis-regulatory elements, DNA methylation or histone modification status of the promoter (41). There are a number of studies regarding miRNAs in SLE. The peripheral blood mononuclear cells from patients with SLE exhibited increases in certain miRNAs (miR-189, miR-61, miR-78, miR-21, miR-142-3p, miR-342, miR-299-3p, miR-198 and miR-298) and decreases in others (miR-196a, miR-17-5p, miR-409-3p, miR-141, miR-383, miR-112 and miR-184) (42). Profiling of the miRNAs expressed in the peripheral blood mononucleated cells (PBMCs) from lupus patients revealed that miR-146a was underexpressed in SLE. A further study found that STAT1 was another target of miR-146a, and there was a reverse correlation of miR-146a levels with the expression of interferon-inducible genes and SLE disease activity (43). miR-3148 could target TLR7 through binding to its 3-untranslated region (3'UTR), which may explain why the 3'UTR of TLR7 mRNA affects its expression in SLE (44). miR-125a was significantly downregulated in PBMCs from SLE patients and promote the secretion of CCL5 by SLE T cells (45). Recent studies showed that distinct expression patterns of miRNAs in peripheral blood leukocytes of SLE patients were associated with different autoantibodies in those SLE patients (46). Another study reported that there were aberrant expression of miRNAs (particularly hsa-miR-371-5p, hsa-miR-423-5p, hsa-miR-638, hsa-miR-1224-3p and hsa-miR-663) in the PBMCs of LN patients across different patients with different 
ethnicities (47). miRNAs $-21,-126$ and -148 a were upregulated in $\mathrm{CD}^{+}$lupus $\mathrm{T}$ cells and there was decreased Dnmt1 expression $(48,49)$. miR-21 was increased in $\mathrm{CD}^{+} \mathrm{T}$ cells from lupus-prone mice. In SLE123 mice models bearing three lupus susceptibility loci from the NZM2410 lupus-prone strain, backcrossed onto a C57BL/6 (B6) background, blocking miR-21 expression decreased splenomegaly (50). A 27-miRNA signature was identified in patients with SLE; 19 miRNAs correlated with disease activity. A total of 8 miRNAs were deregulated specifically in T cells and 4 in B cells. miR-21 was upregulated and strongly correlated with SLE disease activity (51).

Long noncoding RNAs (IncRNAs) are another type of noncoding RNA, which have been studied recently. IncRNAs are defined as transcripts that are non-protein coding transcripts $>200 \mathrm{nt}$ (52). IncRNA are classified into five categories, which are the sense, antisense, intronic, bidirectional lncRNAs and long intergenic ncRNAs (lincRNAs) (53). The functions of IncRNAs in the immune system have been found to be important regulators of the various biological processes in recent studies. IncRNAs have an important role in innate and adaptive immunity (54). SLE is a type of systemic autoimmune diseases, which involves a complicated interaction between the innate and the adaptive immune system loss of immunological tolerance to self-nuclear antigen, and antibody production (55). While there are less lncRNAs reported in SLE, the locations of certain lncRNAs have suggested their involvement in SLE. There are altered expression levels of certain lncRNAs in SLE. For example, linc0949 and linc0597 were significantly decreased in patients with SLE compared with patients with RA and healthy control subjects. Linc0949 was associated with the SLEDAI-2K score, complement component $\mathrm{C} 3$ level and organ damage. Linc0949 was decreased in LN patients (56). This lincRNA may become a biomarker of SLE. The BXSB mouse strain is an important model of glomerulonephritis observed in SLE. In this mice model, the Gas5 gene was underexpressed. Suppressed GAS5 may inhibit the cell cycle and apoptosis. Therefore, it is implicated in autoimmune diseases by leading promotion antigen exposure and production of autoantibodies (57). The GWAS have identified a region on chromosome 1q25 that is associated with SLE. The Gas5 gene is an IncRNA, which is a prime candidate for the chromosome 1q25 SLE locus. Therefore, the genetic evidence demonstrated that GAS5 is associated with the susceptibility of SLE $(58,59)$. Gas5 binds to the DNA-binding domain of the glucocorticoid receptor (GR) by acting as a decoy 'glucocorticoid response element (GRE)', thus, competing with DNA GREs for binding to the GR (59). Therefore, we presume that Gas 5 lncRNA may have an important role in the SLE patients who are insensitive to glucocorticosteroid treatments. GAS5 lncRNA is itself required for mTOR inhibitor action (60). It may be involved in the effects of the tacrolimus treatment for SLE. NeST, formally known as Tmevpg1, is a lincRNA gene located adjacent to the IFN- $\gamma$-encoding gene in mice (Ifng) and humans (IFNG) (61). lincRNA NeST can upregulate the expression of the IFN- $\gamma$ gene in Th1 cells by recruiting H3K4 methyltransferase to the IFN- $\gamma$ locus (61). A previous study showed that the activity index for diffuse proliferative lupus nephritis (DPLN) was correlated with the value of the IFN- $\gamma / \mathrm{IL}-4$ ratio. This indicates that IFN- $\gamma$ has a principal role in the development of DPLN (62). Another study showed that the expression of IFN- $\gamma$ was significantly higher in patients with DPLN (63). We hypothesized that NeST would be involved in the pathomechanism of proliferative $\mathrm{LN}$.

\section{Conclusion}

Evidence has clearly suggested that epigenetic mechanisms are involved in the pathogenesis of SLE. Although significant progress has been made in the field of epigenetics in SLE in the past decades, a number of questions remain to be elucidated. There are numerous studies regarding DNA methylation, histone modification and miRNAs. IncRNAs, which are relatively new, are important for discovering the different expression levels of lncRNAs and the mechanisms in patients with SLE.

\section{Acknowledgements}

The present study was supported by the Graduate Project for Freedom to Explore in Central South University (grant no. 2015zzts113; Hunan, China).

\section{References}

1. Gualtierotti R, Biggioggero M, Penatti AE and Meroni PL: Updating on the pathogenesis of systemic lupus erythematosus. Autoimmun Rev 10: 3-7, 2010.

2. Rahman A and Isenberg DA: Systemic lupus erythematosus. N Engl J Med 358: 929-939, 2008.

3. Harley IT, Kaufman KM, Langefeld CD, Harley JB and Kelly JA: Genetic susceptibility to SLE: New insights from fine mapping and genome-wide association studies. Nat Rev Genet 10: 285-290, 2009.

4. Sestak AL, Fürnrohr BG, Harley JB, Merrill JT and Namjou B: The genetics of systemic lupus erythematosus and implications for targeted therapy. Ann Rheum Dis 70 (Suppl 1): i37-i43, 2011.

5. Mak A and Tay SH: Environmental factors, toxicants and systemic lupus erythematosus. Int J Mol Sci 15: 16043-16056, 2014.

6. Rigante D, Mazzoni MB and Esposito S: The cryptic interplay between systemic lupus erythematosus and infections. Autoimmun Rev 13: 96-102, 2014.

7. Sparks JA and Costenbader KH: Genetics, environment, and gene-environment interactions in the development of systemic rheumatic diseases. Rheum Dis Clin North Am 40: 637-657, 2014.

8. Zan H: Epigenetics in lupus. Autoimmunity 47: 213-214, 2014.

9. Richardson B: Impact of aging on DNA methylation. Ageing Res Rev 2: 245-261, 2003.

10. Egger G, Liang G, Aparicio A and Jones PA: Epigenetics in human disease and prospects for epigenetic therapy. Nature 429: 457-463, 2004.

11. Robertson KD: DNA methylation and human disease. Nat Rev Genet 6: 597-610, 2005.

12. Richardson B, Scheinbart L, Strahler J, Gross L, Hanash S and Johnson M: Evidence for impaired T cell DNA methylation in systemic lupus erythematosus and rheumatoid arthritis. Arthritis Rheum 33: 1665-1673, 1990.

13. Lu Q, Kaplan M, Ray D, Ray D, Zacharek S, Gutsch D and Richardson B: Demethylation of ITGAL (CD11a) regulatory sequences in systemic lupus erythematosus. Arthritis Rheum 46: 1282-1291, 2002.

14. Oelke K, Lu Q, Richardson D, Wu A, Deng C, Hanash S and Richardson B: Overexpression of CD70 and overstimulation of IgG synthesis by lupus $\mathrm{T}$ cells and $\mathrm{T}$ cells treated with DNA methylation inhibitors. Arthritis Rheum 50: 1850-1860, 2004.

15. Richardson B: Primer: Epigenetics of autoimmunity. Nat Clin Pract Rheumatol 3: 521-527, 2007. 
16. Basu D, Liu Y, Wu A, Yarlagadda S, Gorelik GJ, Kaplan MJ, Hewagama A, Hinderer RC, Strickland FM and Richardson BC: Stimulatory and inhibitory killer Ig-like receptor molecules are expressed and functional on lupus T cells. J Immunol 183: 3481-3487, 2009.

17. Lei W, Luo Y, Lei W, Luo Y, Yan K, Zhao S, Li Y, Qiu X, Zhou Y, Long $\mathrm{H}$, et al: Abnormal DNA methylation in $\mathrm{CD}^{+} \mathrm{T}$ cells from patients with systemic lupus erythematosus, systemic sclerosis, and dermatomyositis. Scand J Rheumatol 38: 369-374, 2009.

18. Lu Q, Wu A, Tesmer L, Ray D, Yousif N and Richardson B: Demethylation of CD40LG on the inactive $\mathrm{X}$ in T cells from women with lupus. J Immunol 179: 6352-6358, 2007.

19. Hewagama A, Gorelik G, Patel D, Liyanarachchi P, McCune WJ, Somers E, Gonzalez-Rivera T, Strickland F and Richardson B Michigan Lupus Cohort: Overexpression of X-linked genes in $\mathrm{T}$ cells from women with lupus. J Autoimmun 41: 60-71, 2013.

20. Jeffries MA, Dozmorov M, Tang Y, Merrill JT, Wren JD and Sawalha AH: Genome-wide DNA methylation patterns in $\mathrm{CD} 4^{+} \mathrm{T}$ cells from patients with systemic lupus erythematosus. Epigenetics 6: 593-601, 2011

21. Coit P, Jeffries M, Altorok N, Dozmorov MG, Koelsch KA Wren JD, Merrill JT, McCune WJ and Sawalha AH Genome-wide DNA methylation study suggests epigenetic accessibility and transcriptional poising of interferon-regulated genes in naïve $\mathrm{CD}^{+} \mathrm{T}$ cells from lupus patients. J Autoimmun 43 : 78-84, 2013

22. Chung SA, Nititham J, Elboudwarej E, Quach HL, Taylor KE, Barcellos LF and Criswell LA: Genome-wide assessment of differential DNA methylation associated with autoantibody production in systemic lupus erythematosus. PLoS One 10 e0129813, 2015.

23. Chan RW, Jiang P, Peng X, Tam LS, Liao GJ, Li EK, Wong PC Sun $\mathrm{H}$, Chan KC, Chiu RW, et al: Plasma DNA aberrations in systemic lupus erythematosus revealed by genomic and methylomic sequencing. Proc Natl Acad Sci USA 111: E5302-E5311, 2014.

24. Jenuwein $\mathrm{T}$ and Allis CD: Translating the histone code Science 293: 1074-1080, 2001

25. Javierre BM, Fernandez AF, Richter J, Al-Shahrour F Martin-Subero JI, Rodriguez-Ubreva J, Berdasco M, Fraga MF, O'Hanlon TP, Rider LG, et al: Changes in the pattern of DNA methylation associate with twin discordance in systemic lupus erythematosus. Genome Res 20: 170-179, 2010.

26. Zhang Z, Song L, Maurer K, Petri MA and Sullivan KE: Global $\mathrm{H} 4$ acetylation analysis by ChIP-chip in systemic lupus erythematosus monocytes. Genes Immun 11: 124-133, 2010.

27. Pieterse E, Hofstra J, Berden J, Herrmann M, Dieker J and van der Vlag J: Acetylated histones contribute to the immunostimulatory potential of neutrophil extracellular traps in systemic lupus erythematosus. Clin Exp Immunol 179: 68-74, 2015.

28. Mamula MJ, Gee RJ, Elliott JI, Sette A, Southwood S, Jones PJ and Blier PR: Isoaspartyl post-translational modification triggers autoimmune responses to self-proteins. J Biol Chem 274: 22321-22327, 1999.

29. Doyle HA, Aswad DW and Mamula MJ: Autoimmunity to isomerized histone $\mathrm{H} 2 \mathrm{~B}$ in systemic lupus erythematosus. Autoimmunity 46: 6-13, 2013.

30. Liu CL, Tangsombatvisit S, Rosenberg JM, Mandelbaum G, Gillespie EC, Gozani OP, Alizadeh AA and Utz PJ: Specific post-translational histone modifications of neutrophil extracellular traps as immunogens and potential targets of lupus autoantibodies. Arthritis Res Ther 14: R25, 2012.

31. Apostolidis SA, Rauen T, Hedrich CM, Tsokos GC and Crispín JC: Protein phosphatase 2A enables expression of interleukin 17 (IL-17) through chromatin remodeling. J Biol Chem 288: 26775-26784, 2013.

32. White CA, Pone EJ, Lam T, Tat C, Hayama KL, Li G, Zan H and Casali P: Histone deacetylase inhibitors upregulate $\mathrm{B}$ cell microRNAs that silence AID and Blimp-1 expression for epigenetic modulation of antibody and autoantibody responses. J Immunol 193: 5933-5950, 2014.

33. Regna NL, Chafin CB, Hammond SE, Puthiyaveetil AG, Caudell DL and Reilly CM: Class I and II histone deacetylase inhibition by ITF2357 reduces SLE pathogenesis in vivo. Clin Immunol 151: 29-42, 2014

34. Yang Y, Tang Q, Zhao M, Liang G, Wu H, Li D, Xie Y, Tan Y, Dai Y, Yung S, et al: The effect of mycophenolic acid on epigenetic modifications in lupus $\mathrm{CD}^{+} \mathrm{T}$ cells. Clin Immunol 158: 67-76, 2015 .
35. Mir AR and Moinuddin: Glyoxidation of histone proteins in autoimmune disorders. Clin Chim Acta 450: 25-30, 2015.

36. Khan MA, Dixit K, Moinuddin, Arif Z and Alam K: Studies on peroxynitrite-modified H1 histone: Implications in systemic lupus erythematosus. Biochimie 97: 104-113, 2014.

37. Alzolibani AA, Al Robaee AA, Al-Shobaili HA and Rasheed Z: 4-Hydroxy-2-nonenal modified histone-H2A: A possible antigenic stimulus for systemic lupus erythematosus autoantibodies. Cell Immunol 284: 154-162, 2013.

38. Moran VA, Perera RJ and Khalil AM: Emerging functional and mechanistic paradigms of mammalian long non-coding RNAs. Nucleic Acids Res 40: 6391-6400, 2012.

39. Ørom UA, Derrien T, Beringer M, Gumireddy K, Gardini A, Bussotti G, Lai F, Zytnicki M, Notredame C, Huang Q, et al: Long noncoding RNAs with enhancer-like function in human cells. Cell 143: 46-58, 2010.

40. Sun L,GoffLA, TrapnellC,Alexander R,LoKA,HacisuleymanE, Sauvageau M, Tazon-Vega B, Kelley DR, Hendrickson DG, et al: Long noncoding RNAs regulate adipogenesis. Proc Natl Acad Sci USA 110: 3387-3392, 2013.

41. Davis-Dusenbery BN and Hata A: Mechanisms of control of microRNA biogenesis. J Biochem 148: 381-392, 2010.

42. Dai Y, Huang YS, Tang M, Lv TY, Hu CX, Tan YH, Xu ZM and Yin YB: Microarray analysis of microRNA expression in peripheral blood cells of systemic lupus erythematosus patients. Lupus 16: 939-946, 2007.

43. Tang Y, Luo X, Cui H, Ni X, Yuan M, Guo Y, Huang X, Zhou H, de Vries N, Tak PP, et al: MicroRNA-146A contributes to abnormal activation of the type I interferon pathway in human lupus by targeting the key signaling proteins. Arthritis Rheum 60: 1065-1075, 2009

44. Deng Y,Zhao J,Sakurai D,KaufmanKM,Edberg JC,Kimberly RP, Kamen DL, Gilkeson GS, Jacob CO, Scofield RH, et al: MicroRNA-3148 modulates allelic expression of toll-like receptor 7 variant associated with systemic lupus erythematosus. PLoS Genet 9: e1003336, 2013.

45. Zhao X, Tang Y, Qu B, Cui H, Wang S, Wang L, Luo X, Huang X, Li J, Chen S, et al: MicroRNA-125a contributes to elevated inflammatory chemokine RANTES levels via targeting KLF13 in systemic lupus erythematosus. Arthritis Rheum 62: 3425-3435, 2010

46. Chauhan SK, Singh VV, Rai R, Rai M and Rai G: Differential microRNA profile and post-transcriptional regulation exist in systemic lupus erythematosus patients with distinct autoantibody specificities. J Clin Immunol 34: 491-503, 2014.

47. Te JL, Dozmorov IM, Guthridge JM, Nguyen KL, Cavett JW, Kelly JA, Bruner GR, Harley JB and Ojwang JO: Identification of unique microRNA signature associated with lupus nephritis. PLoS One 5: e10344, 2010.

48. Pan W, Zhu S, Yuan M, Cui H, Wang L, Luo X, Li J, Zhou H, Tang $Y$ and Shen N: MicroRNA-21 and microRNA-148a contribute to DNA hypomethylation in lupus $\mathrm{CD} 4^{+} \mathrm{T}$ cells by directly and indirectly targeting DNA methyltransferase 1 . J Immunol 184: 6773-6781, 2010.

49. Zhao S, Wang Y, Liang Y, Zhao M, Long $H$, Ding S, Yin $H$ and Lu Q: MicroRNA-126 regulates DNA methylation in $\mathrm{CD} 4^{+} \mathrm{T}$ cells and contributes to systemic lupus erythematosus by targeting DNA methyltransferase 1 . Arthritis Rheum 63: 1376-1386, 2011

50. Garchow BG, Bartulos Encinas O, Leung YT, Tsao PY Eisenberg RA, Caricchio R, Obad S, Petri A, Kauppinen S and Kiriakidou M: Silencing of microRNA-21 in vivo ameliorates autoimmune splenomegaly in lupus mice. EMBO Mol Med 3: 605-615, 2011.

51. Stagakis E, Bertsias G, Verginis P, Nakou M, Hatziapostolou M, Kritikos H, Iliopoulos D and Boumpas DT: Identification of novel microRNA signatures linked to human lupus disease activity and pathogenesis: miR-21 regulates aberrant $\mathrm{T}$ cell responses through regulation of PDCD4 expression. Ann Rheum Dis 70: 1496-1506, 2011

52. Perkel JM: Visiting 'noncodarnia'. Biotechniques 54: 301, 303-304, 2013.

53. Kaikkonen MU, Lam MT and Glass CK: Non-coding RNAs as regulators of gene expression and epigenetics. Cardiovasc Res 90: 430-440, 2011.

54. Fitzgerald KA and Caffrey DR: Long noncoding RNAs in innate and adaptive immunity. Curr Opin Immunol 26: 140-146, 2014.

55. Liu CC, Kao AH, Manzi S and Ahearn JM: Biomarkers in systemic lupus erythematosus: Challenges and prospects for the future. Ther Adv Musculoskelet Dis 5: 210-233, 2013. 
56. Wu Y, Zhang F, Ma J, Zhang X, Wu L, Qu B, Xia S, Chen S, Tang Y and Shen N: Association of large intergenic noncoding RNA expression with disease activity and organ damage in systemic lupus erythematosus. Arthritis Res Ther 17: 131, 2015.

57. Haywood ME, Rose SJ, Horswell S, Lees MJ, Fu G, Walport MJ and Morley BJ: Overlapping BXSB congenic intervals, in combination with microarray gene expression, reveal novel lupus candidate genes. Genes Immun 7: 250-263, 2006

58. Suarez-Gestal M, Calaza M,Endreffy E, Pullmann R, Ordi-Ros J, Sebastiani GD, Ruzickova S, Jose Santos M, Papasteriades C, Marchini M, et al; European Consortium of SLE DNA Collections: Replication of recently identified systemic lupus erythematosus genetic associations: A case-control study. Arthritis Res Ther 11: R69, 2009.

59. Kino T, Hurt DE, Ichijo T, Nader N and Chrousos GP: Noncoding RNA gas 5 is a growth arrest- and starvation-associated repressor of the glucocorticoid receptor. Sci Signal 3: ra8, 2010.
60. Yacqub-Usman K, Pickard MR and Williams GT: Reciprocal regulation of GAS5 lncRNA levels and mTOR inhibitor action in prostate cancer cells. Prostate 75: 693-705, 2015.

61. Gomez JA, Wapinski OL, Yang YW, Bureau JF, Gopinath S, Monack DM, Chang HY, Brahic M and Kirkegaard K: The NeST long ncRNA controls microbial susceptibility and epigenetic activation of the interferon- $\gamma$ locus. Cell 152: 743-754, 2013.

62. Masutani K, Taniguchi M, Nakashima H, et al: Upregulated interleukin-4 production by peripheral T-helper cells in idiopathic membranous nephropathy. Nephrol Dial Transplant 19: 580-586, 2004

63. Chan RW, Lai FM, Li EK, et al: Intrarenal cytokine gene expression in lupus nephritis. Ann Rheum Dis 66: 886-892, 2007. 